\title{
An advisory tool to improve management practices affecting calf and heifer welfare on dairy farms
}

\author{
E. Vasseur, ${ }^{\dagger}{ }^{1}$ J. Rushen, $\dagger$ A. M. de Passillé, $\dagger$ D. Lefebvre, $\ddagger$ and D. Pellerin* \\ *Animal Sciences Department, Laval University, Quebec, Quebec, Canada, G1K 7P4 \\ †Pacific Agri-Food Research Centre, Agriculture and Agri-Food Canada, Agassiz, British Columbia, Canada, V0M 1A0 \\ $\ddagger$ Valacta, Dairy Production Centre of Expertise Quebec-Atlantic, Sainte-Anne-de-Bellevue, Quebec, Canada, H9X 3R4
}

\begin{abstract}
We developed an advisory tool addressing 10 critical areas of calf and heifer management, including calving management, care to newborn calves and painful procedures, colostrum management, cow-calf separation, calf feeding, weaning, calf housing, heifer feeding, heifer housing, and general monitoring. Targets and indicators for each critical area were validated by a panel of experts and maximum scores were assigned based on experts' opinions and reviews of scientific literature. The tool was tested on 28 Quebec dairy farms for feasibility and repeatability between 2 observers. Farmers were asked to test colostrum quality, measure blood IgG concentrations, and record health events. The on-farm evaluation included an interview on management practices and an evaluation of conditions in the barn. Scorings and recommendations were discussed with producers. The usefulness of our on-farm welfare tool was evaluated by the producers themselves during a final debriefing. We reached the main goals of a successful advisory tool of calf and heifer management to improve welfare on dairy farms. We respected the targeted time limit of a 3 -h visit covering all aspects of our tool including data collection on management and environment, scoring, practical demonstration with producers, and debriefing. We had no problems collecting management- and environment-based data and had high repeatability of qualitative environment-based measures (kappa value $>0.6$ ). Our tool helped to detect problems and to discuss these problems with the producers; producers scored below $50 \%$ for some targets in calving management, care to newborn calves and painful procedures, colostrum management, and calf feeding. The targets were realistic so producers were not discouraged. All producers were convinced of the usefulness of our tool for identifying areas of calf and heifer management in need of improvement. They were also convinced of the usefulness of our tool as an advisory tool for technical
\end{abstract}

Received July 23, 2009.

Accepted April 21, 2010.

${ }^{1}$ Corresponding author: vasseur.elsa@gmail.com advisors and veterinarians. Six months after the onfarm visit, recommended practices were implemented in many of these areas. Voluntary improvements in animal welfare can be facilitated by using appropriate tools to educate producers and help them change their attitudes toward calf management and animal welfare.

Key words: on-farm tool, welfare, management, calf

\section{INTRODUCTION}

In response to growing public interest in farm animal welfare, the European Union has enacted legislation to protect farm animals during slaughter, transport, and rearing (Veissier et al., 2008). However, because there are differences between farms in the level of animal welfare achieved and in the types of welfare problems encountered, a legislative approach, which defines minimum requirements for all farms, may not be effective at solving problems that are specific to individual farms. Animal welfare audits based on a hazard analysis at critical control points approach (e.g., von Borell et al., 2001; Stull et al., 2005) may be more effective in helping to identify problems on a specific farm and helping the farm improve its practices. Once problems have been identified, there is a need for intervention at the farm level to improve the welfare of the animals.

The first step in a strategy to improve animal welfare at the farm level is to conduct a risk assessment that identifies the main risks to animal welfare within a particular population of farms (Whay, 2007). Mortality and morbidity are high among dairy calves in North America (USDA, 2008), which is costly (Tozer and Heinrichs, 2001) and causes concern for the welfare of these animals. However, whereas welfare assessment schemes are available for dairy cows (e.g., Whay et al., 2003), none are yet available for calves and heifers. In a previous survey of calf and heifer management practices on Quebec dairy farms (Vasseur et al., 2010), we identified several management practices commonly used that could adversely affect calf welfare.

The objective of this study was to assess an advisory tool that has been developed to help dairy producers 
Table 1. Main characteristics of our sample (no. of herds = 28)

\begin{tabular}{lc}
\hline Characteristic & Sample \\
\hline Breed, $\%$ & 79 \\
Holstein & 21 \\
Ayrshire & 43 \\
Size, $\%$ & 57 \\
Small ( $\leq 100$ head) & $9,492 \pm 1,069^{1}$ \\
Large $(>100$ head) & 11 \\
Milk production, kg/cow per year & 43 \\
Full-time employees, \% & 35 \\
1 & 11 \\
2 & \\
3 & 60 \\
$>3$ & 40 \\
Person in charge of calves and heifers, $\%$ & $42 \pm 12^{1}$ \\
Producer & 40 \\
Other & 36 \\
Age of person in charge of calves and heifers, yr & 24 \\
Agricultural education of person in charge of calves and heifers, $\%$ & \\
None & \\
High school & \\
College or higher &
\end{tabular}

detect problems with their calf and heifer rearing methods that pose a risk to animal welfare and to encourage producers to adopt better practices. In our assessment of this tool, we considered both the feasibility of using it on farms and the likelihood that it would be implemented by advisors and producers. We established several goals that would need to be met if the tool was to be implemented successfully. One set of goals dealt with the feasibility of using the tool on commercial dairy farms. First, use of the tool on farms should be completed within a realistic time limit. We considered that $3 \mathrm{~h}$ on farm is the maximum time for a visit that would be considered acceptable by both producers and advisors, mainly from a financial point of view. Second, the data should be easily collected and the measures taken should be repeatable. To be used routinely by both producers and advisors, measures need to be easily taken at the farm level, and if qualitative measures are involved, then their assessment should be repeatable enough to ensure a uniform evaluation between different advisors. The second set of goals dealt with the likelihood that the tool would be used by advisors and producers. For the tool to be used, the targets set need to be realistic so that dairy producers should be able to meet them without becoming discouraged. However, the targets should not be so low that real problems are not detected. Furthermore, the producers should consider the advisory tool as being useful to them. The final goal was that use of the tool should result in changes in management where necessary. We assessed our tool based on the extent that these goals were met.

\section{MATERIALS AND METHODS}

\section{Farm Sampling}

Twenty-eight dairy farms located within $100 \mathrm{~km}$ of Laval University (Quebec City, Quebec, Canada) volunteered to participate in our project. We chose farms that were representative of the range of farm sizes in Quebec. Table 1 shows the main characteristics of our sample.

\section{Development of the Tool}

Identification of Critical Areas of Management. Our methodology was inspired by hazard analysis of critical control points approaches applied to animal welfare (e.g., von Borell et al., 2001). Based on the results of our previous epidemiological survey in Quebec (Vasseur et al., 2010), we identified several critical areas where producers used management practices that could adversely affect calf welfare and where improvements could be made. The critical areas identified were calving management, care to newborn calves and use of painful procedures, colostrum management, cow-calf separation, calf feeding, weaning, calf housing, heifer feeding, heifer housing, and general monitoring (Tables 2, 3, and 4).

Determination of Targets. Each of these 10 critical areas comprised several targets that producers should reach to improve their management practices and animal welfare (Tables 2, 3, and 4). Targets were based on the available scientific information. For example, considerable research has shown that the timing 


\begin{tabular}{|c|c|c|c|c|}
\hline Critical area & Target & $\begin{array}{l}\text { Maximum } \\
\text { score }\end{array}$ & $\begin{array}{l}\text { Indicator comprising measures taken } \\
\text { during interview with producer }(\mathrm{n})\end{array}$ & $\begin{array}{l}\text { Indicator comprising measures taken } \\
\text { by observer during visits to barn (n) }\end{array}$ \\
\hline \multirow[t]{5}{*}{ Calving management } & High calving surveillance level & 35 & Calving checks (2) & \\
\hline & Use of calving pen on a regular basis & 30 & Calving area type and use (1) & \\
\hline & $\begin{array}{l}\text { Appropriate calving pen management } \\
\text { for sick animals }\end{array}$ & 8 & Calving area used as hospital pen (1) & \\
\hline & High calving pen cleanliness level & 18 & \multirow{2}{*}{ Calving area litter management (2) } & Calving area cleanliness estimation (1) \\
\hline & Comfort and ergonomic quality of calving pen & 9 & & $\begin{array}{l}\text { Calving area dimensions (1); } \\
\text { safety hazards }(1)\end{array}$ \\
\hline \multirow{3}{*}{$\begin{array}{l}\text { Care to newborn } \\
\text { calves and painful } \\
\text { procedures }\end{array}$} & Immediate disinfection on a regular basis & 44 & Navel disinfection timing (1) & \\
\hline & Immediate identification on a regular basis & 8 & Calf identification timing (1) & \\
\hline & Appropriate painful procedure management & 48 & $\begin{array}{l}\text { Use of a dehorning standard operating } \\
\text { procedure (4); dehorning timing (1); } \\
\text { use of analgesic, anesthetic, or sedative } \\
\text { for dehorning (1); tail docking (1) }\end{array}$ & \\
\hline \multirow{8}{*}{$\begin{array}{l}\text { Colostrum } \\
\text { management }\end{array}$} & First feeding within first $4 \mathrm{~h}$ of calf's life & 33 & First colostrum meal timing (1) & \\
\hline & Monitoring of quantity ingested at first feeding & 11 & First colostrum meal quantity (1) & \\
\hline & $\begin{array}{l}\text { Feeding of at least } 4 \mathrm{~L} \text { of first-milking } \\
\text { colostrum within first } 12 \mathrm{~h} \text { of life }\end{array}$ & 18 & $\begin{array}{l}\text { Total colostrum quantity (1); use } \\
\text { of first-milking colostrum (1) }\end{array}$ & \\
\hline & $\begin{array}{l}\text { Use of a method by means of which a controlled } \\
\text { quantity of colostrum can be given }\end{array}$ & 11 & Method (1) & \\
\hline & $\begin{array}{l}\text { Feeding of a smaller quantity (up to } 2 \text { L) only } \\
\text { in case of difficulty and colostrum of excellent } \\
\text { quality; otherwise, use of esophageal feeder }\end{array}$ & 7 & Alternative method (1) & \\
\hline & $\begin{array}{l}\text { Routine assessment of colostrum quality with } \\
\text { a colostrometer }\end{array}$ & 6 & Evaluation of colostrum quality (1) & \\
\hline & $\begin{array}{l}\text { Routine supply of adequate stocks } \\
\text { of frozen colostrum }\end{array}$ & 11 & Stocks of colostrum (2) & \\
\hline & Routine verification of immunity transfer & 3 & Check of passive transfer (1) & \\
\hline
\end{tabular}

Monitoring of quantity ingested at first feeding

Feeding of at least $4 \mathrm{~L}$ of first-milking

Use of a method by means of which a controlle

quantity of colostrum can be given

作

outine supply of

Routine verification of immunity transfer 
Table 3. Critical areas, targets, maximum possible score attributed to each target, and descriptions of indicators comprising measures taken during the interview with the producer and indicators comprising measures taken by the observers during the visit to the barn

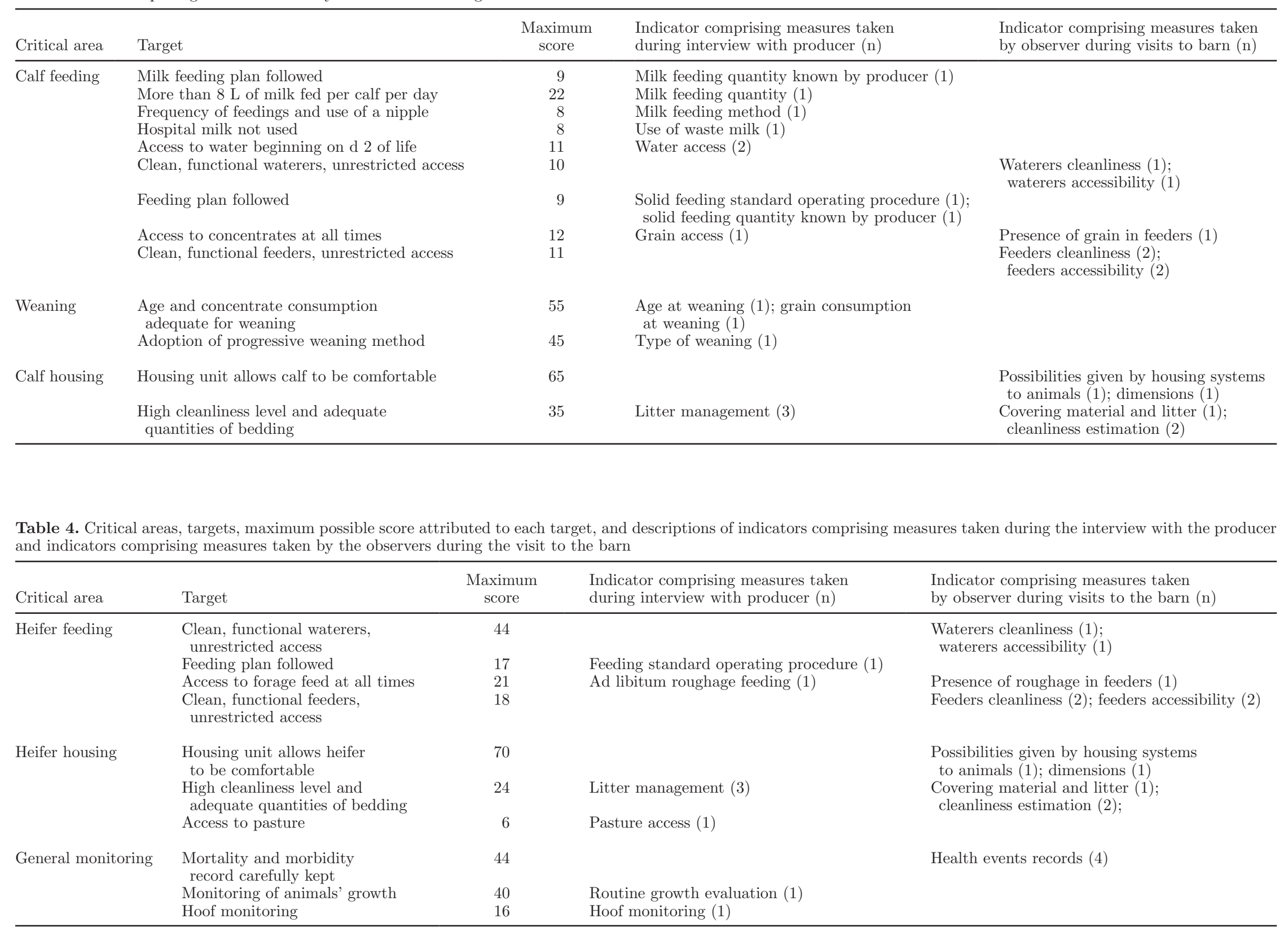


of the first meal of colostrum is critical because optimal absorption of immunoglobulins occurs before $4 \mathrm{~h}$ of age and decreases rapidly after $12 \mathrm{~h}$ (Weaver et al., 2000). Thus, we defined a target (Table 2) as "first feeding of colostrum within first $4 \mathrm{~h}$ of calf's life" for the critical area "colostrum management."

Definition of Indicators. Once targets were established, we then defined indicators (Tables 2, 3, and 4; Mitchell et al., 1995) that consisted of 1 or a combination of measures that determined the extent to which a target is reached (which could range from 0 to $100 \%$ ). These indicators were based on answers to questions that were asked in the interview of the producer and on observations that were made during a visit to the facilities housing the calves and heifers (Tables 2, 3, and 4$)$.

The answers to the questions during the interview were either qualitative nominal (e.g., "Do you check colostrum quality using a colostrometer?" Answer: yes vs. no), qualitative ordinal [e.g., "When do you provide colostrum for the first time?" Scale of answers: 1 ("within $2 \mathrm{~h}$ of life") to 5 ("never")], or continuous (e.g., "Which quantity of colostrum is given for the first feeding?" Answer: number of liters of colostrum).

During the visit to the rearing facilities, the observer scored conditions in the barn using a questionnaire. The answers to the questions were either qualitative nominal (e.g., "Are there any safety hazards in the calving area?" Answer: yes vs. no), qualitative ordinal [e.g., "How much accumulated manure is there in the calving area?" Scale of answers: 1 ("none") to 5 ("entire area contaminated")], or continuous (e.g., "What are the dimension of the calving area?" Answer: number of meters of calving pen length and width).

The answers to the interview questions and the observations taken during the visit were then used to assess the extent that the targets had been reached. For example, the indicator for the target "first feeding of colostrum within $4 \mathrm{~h}$ of calf's life" was the producer's answer to the question "When do you give colostrum for the first time?" Possible answers were A) within $2 \mathrm{~h}$ of life (target reached at 100\%), B) between 2 and $6 \mathrm{~h}$ $(66 \%), \mathrm{C})$ between 6 and $12 \mathrm{~h}(33 \%), \mathrm{D})$ the day after the birth (0\%), and E) never $(0 \%)$.

Some questions could be used in only some situations. For example, the question on the accumulation of manure in the calving pen was relevant only if a calving pen was in use, which we could not predict would be the case in any given visit. This question was used in discussions with the producer but did not enter in the scoring. Where possible, we checked the answers to the questions posed in the interview. For example, if the producers claimed to disinfect the calves' navels with iodine, then the observer should be able to find iodine in the barn and identify the name of the product and the location and cleanliness of the container. When discrepancies were found, these were discussed with the producers to clarify their practices.

The questionnaires used for the collection of data and the observations were tested previously on 115 dairy farms in Quebec (Vasseur et al., 2010) and reviewed and tested again in 60 farms in central Europe (Winckler et al., 2006). In identifying the critical areas, targets, and indicators, we relied on several recent reviews of the factors affecting calf welfare (EFSA, 2006; Rushen et al., 2008; NFACC, 2009).

Design Validation of the Tool by a Panel of Experts. We organized a focus group of 6 experts of several fields related to dairy production (an agronomist, a dairy producer, a veterinarian, a technical advisor, and 2 researchers). The first objective of this meeting was the design or conceptual validation of our tool (Bockstaller and Girardin, 2003) to judge the scientific quality of the construction of the tool. The expert group examined and discussed the questions, indicators, and critical areas until the group reached a consensus. The group then assigned maximum possible scores for each target (see Score Assignment). We also submitted for review all the components of our tool (e.g., data recording sheets, material distributed to producers) until the group arrived at a consensus. The second objective of this meeting was a discussion of the recommendations to be provided to producers. The full list of questions and variables measured during the survey of the facilities is available from the first author and is publicly available online (www.agrireseau.qc.ca/ bovinslaitiers).

Score Assignment. We assumed that all critical areas are equally important for animal welfare and so we gave them equal weighting and assigned a maximum possible score of 100 to all of them. We then asked each of the 6 experts to independently weight the targets within each critical area and give each a maximum possible score so that the sum of all scores of the targets with each critical area added up to 100 . We then took the median of the scores from the 6 experts (Tables 2, 3 , and 4). Within a specific target, we considered all indicators as equally important. Therefore, to obtain a maximum possible score for each indicator, we divided the maximum score for the target by the number of indicators.

During the visit to the farm, we scored each farm for each critical area and target based on the producer's answers to the questions on management and on the evaluation of the conditions in the barn. This scoring was discussed with the producer at the end of the onfarm visit. For each target we explained the research that had been done, which supported our scoring. We 
provided a report to the producers, who could forward it to advisors or consultants.

Tasks Assigned to Producers. To encourage the producers to take an active part in the project, we asked them to take and test samples of calves' blood and of colostrum and to record health events. Each producer involved in the study was trained to fill records and perform the required tests, and standard operating procedures were provided. The tasks assigned to producers included the following:

a) Filling complete records of the newborn management. We asked producers to record all steps of newborn calf management in a "calf passport." The 5 steps of the newborn management recorded were 1) information related to birth and calving (intervention at calving, birth timing, and calf seen suckling), 2) identification (calf and dam), 3) checking dam's colostrum quality (time of sampling, quality test), 4) colostrum feeding (timing, quantity, origin, and method), and 5) checking passive transfer of immunity (blood sampling and Ig test).

b) Taking samples of colostrum. Producers were asked to keep 5 samples of colostrum to test the colostrum quality (poor, medium, or high quality) by using a colostrometer (Kruuse Colostrum Densimeter, Langeskov, Denmark), which we supplied to them, and to report these results in the calf passport.

c) Taking blood samples. Producers were asked to take a blood sample following recommended procedure (Vasseur et al., 2009a) for 5 calves 24 to $48 \mathrm{~h}$ after colostrum feeding and to test the Ig levels in blood using an easily used kit (Whole Blood Calf IgG Midland Quick Test Kit, Midland BioProducts Corp., Boone, IA). This was to check the passive transfer of immunity (pass vs. fail). Producers were asked to record the result in the calf passport.

d) Keeping health and mortality records. Farmers were asked to record each instance of calf mortality and morbidity (diarrhea, respiratory disease, or other, and treatments) during a 6-mo period.

Sequence of the On-Farm Visit. The on-farm visit was conducted in 6 steps and we targeted a total duration of $3 \mathrm{~h}$. Steps included 1) interview with the producer on management (evaluation of management practices; target duration: $30 \mathrm{~min}$ ), 2) tour of facilities with the producer (target duration: $15 \mathrm{~min}$ ), 3) evaluation of conditions in the barn (target duration: $1 \mathrm{~h}$ ), 4) scoring (target duration: 5 min), 5) checking colostrum samples with the producer (target duration: $15 \mathrm{~min}$ ), and 6) debriefing with the producer (target duration: $30 \mathrm{~min})$.

\section{On-Farm Test of the Tool}

Feasibility and Interobserver Repeatability Analysis. The feasibility analysis was based on the timing (e.g., did we respect the targeted $3 \mathrm{~h}$-time limit?) and our ability to take the measures (e.g., did we have physical constraints to collecting data?). We also tested interobserver repeatability of qualitative environment-based measures (e.g., judging cleanliness of a nonweaned calves pen using a scale of definition of cleanliness). We used 2 well-trained observers who used the tool simultaneously but independently on the 28 farms and we compared the 2 sets of scores.

Effectiveness as Judged by the End User. The final step of our on-farm visit was an interview to collect producers' perception of the usefulness of our tool. We asked questions about the ease of use, the time and cost involved, the producer's degree of interest, and the routine use of tested material (calf passport, colostrometer, Ig blood test, and health record). We also asked questions on the overall diagnostic tool and scoring system (e.g., the relative scores attributed to targets). We used scales of perceptions (qualitative ordinal data) and open questions (e.g., "Do you have suggestions to improve calf passport? Yes/no and explain your answer"). Producers could point out the weaknesses of the indicators and components of the tool as a diagnostic or decision aid tool. The effectiveness was also judged by analyzing producers' scoring. To have realistic targets, we aimed to have most scores in the middle of the range (i.e., if most producers scored close to $100 \%$, we probably missed problems, whereas if most producers scored close to $0 \%$, then our targets were probably unrealistic). In addition, we judged the extent to which our recommendations had been adopted after 6 mo. This was tested with a short survey conducted during a final meeting of results presentation to our sample of 28 producers or by phone 6 mo after the on-farm visit. This short survey asked questions about 15 targeted practices (e.g., "Do you routinely apply a record of mortality and morbidity events?"); the answers proposed to producers were qualitative nominal (e.g., yes vs. no).

Statistical Analysis. Descriptive statistics were used to analyze producers' scoring; the minimum, 25th percentile, median, 75 th percentile, and maximum were calculated. Percentages were calculated for the analysis of the questionnaires and producers' perception. Kappa coefficients were calculated for interobserver repeatability analysis using the SAS statistical package (version 9.1, SAS Institute Inc., Cary, NC). A single kappa 
Table 5. The mean duration of each step of the visit

\begin{tabular}{lcrr}
\hline Step, min & No. of herds & Mean & SD \\
\hline Evaluation of management practices & 28 & 29 & 12 \\
Tour of facilities with producer & 28 & 19 & 8 \\
Evaluation of conditions in the barn & 28 & 30 & 11 \\
Scoring & 27 & 25 & 6 \\
Test colostrum quality with producer & 23 & 43 & 26 \\
Debriefing with producer & 26 & 50 & 16 \\
Total visit & 25 & 187 & 54 \\
\hline
\end{tabular}

value $(\mathbf{K})$ was calculated if each observer took only 1 measure on each farm. In some cases, each observer took more than 1 measure on each farm. For example, "litter quantity" in calf housing was assessed a total of 40 times for the 28 farm visits because there was more than 1 pen per farm so 1 measure was taken for each pen. In this case, a kappa value was calculated for each measure and the median kappa value was calculated. In some cases, measures could not be taken on all farms. For example, "litter quantity" in calving pen was assessed a total of 16 times for the 28 farms; indeed, only 16 farms had a calving pen. We followed Harbison et al. (2002) and Rousing and Waiblinger (2004) in using the following classification for the interpretation of kappa value: high concordance (high repeatability between 2 judges; $\mathrm{K}>0.6)$, moderate concordance $(0.6>\mathrm{K}>$ $0.4)$, and low concordance $(\mathrm{K}<0.4)$.

\section{RESULTS AND DISCUSSION}

We present our results in terms of whether we achieved the main goals related to the feasibility of using the tool on commercial farms and the likelihood that it would be used by advisors or producers to improve management practices.

\section{Duration of Visit}

The time needed to conduct the on-farm visit is a determining factor of the feasibility of the tool. Our goal was to complete the visit in no more than $3 \mathrm{~h}$. In the case of an audit, $3 \mathrm{~h}$ (equivalent to a half-working day for a dairy producer, excluding milking) is probably the maximum time that is acceptable from a practical and financial point of view. Table 5 shows the duration of each step of the visit (mean $\pm \mathrm{SD}$ ). We came close to meeting our goal with total visit duration of 3 to 4 $\mathrm{h}$. However, debriefing took twice as long as expected (around $1 \mathrm{~h}$ instead of $30 \mathrm{~min}$ ), mainly because the producers were interested in understanding all the steps of our tool and the scoring in detail, which led to much discussion between the producers and the observers. This discussion is good but it increased the duration of the visit. However, this tool should encourage discussion between producers and advisors about areas in need of improvement, and this was the case.

Checking colostrum samples took a long time (about $40 \mathrm{~min}$ ), but this step could be removed in routine use of the tool. We wanted to ensure that producers went through all steps of good colostrum management because colostrum management was identified as a major area in need of improvement in our risk factor assessment (Vasseur et al., 2010) and is an important area of concern for calf and heifer welfare (e.g., EFSA, 2006; NFACC, 2009). As a result of the visit, all producers understood very well the importance of checking colostrum quality, which was reflected in the producers' perceptions and long-term effects of the tool.

\section{Ease of Data Collection and Repeatability of Qualitative Assessments}

No major problems were encountered in collecting the management- and environment-based data. This is likely because both questionnaires were well developed and well tested before this experiment.

To judge the accuracy of any measure, especially qualitative measures (e.g., judging the cleanliness of a pen), it is necessary to test the repeatability between several observers (e.g., Lensink et al., 2003; March et al., 2007). If a variable is not repeatable between 2 observers, this would result in errors of judgments and so this variable could not be used in an on-farm assessment tool that required several users (De Rosa et al., 2003). The qualitative environment-based measures (evaluation of conditions in the barn) included judgments of the quantity of cover litter, the accumulation of manure, the cleanliness of the pens, and the cleanliness and accessibility of feeders. We obtained high repeatability $(\mathrm{K}>0.6)$ for all qualitative environment-based measures (Table 6) except for judging the accumulation of manure and judging the quantity of litter in heifer housing, for which we obtained only moderate repeatability $(0.6>$ Kappa value $>0.4)$. To improve these assessments, we have now developed visual charts (not tested on the farms involved in this study) to help standardize judgments between observers and between farms for future use of the tool.

\section{Having Realistic Targets}

For the tool to be useful, the targets set should be realistic and not be so high as to discourage producers. However, the targets should not be set so low that all producers reach them easily even if they have real problems on their farm. We considered that the targets would be realistic if average scores were in the middle 
Table 6. Repeatability between 2 observers for qualitative environment measures describing calving pen, calf housing, and heifer housing

\begin{tabular}{lll}
\hline Measure & $\mathrm{K}$ & $\mathrm{N}^{1}$ \\
\hline Calving pen & & \\
Litter quantity & $0.854^{2}$ & 16 \\
Manure accumulation & $0.807^{2}$ & 16 \\
Pen cleanliness & $0.898^{2}$ & 16 \\
Calf housing & & \\
Milk bucket/distributor cleanliness & $0.863^{2}$ & 24 \\
Waterer cleanliness & $0.582^{2}$ & 22 \\
Waterer accessibility & $0.854^{2}$ & 28 \\
Roughage feeder cleanliness & $0.524^{2}$ & 21 \\
Roughage feeder accessibility & $0.565^{2}$ & 28 \\
Grain feeder cleanliness & $0.596^{2}$ & 23 \\
Grain feeder accessibility & $0.867^{2}$ & 27 \\
Litter quantity & $0.652^{3}$ & 40 \\
Manure accumulation & $0.389^{3}$ & 40 \\
Pen cleanliness & $0.532^{3}$ & 40 \\
Heifer housing & & \\
Waterer cleanliness & $0.618^{3}$ & 80 \\
Waterer accessibility & $0.618^{2}$ & 28 \\
Roughage feeder cleanliness & $0.667^{3}$ & 82 \\
Roughage feeder accessibility & $1.000^{3}$ & 83 \\
Grain feeder cleanliness & $0.786^{3}$ & 83 \\
Grain feeder accessibility & $1.000^{3}$ & 83 \\
Litter quantity & $0.309^{3}$ & 102 \\
Manure accumulation & $0.338^{3}$ & 103 \\
Pen cleanliness & $0.734^{3}$ & 103 \\
\hline
\end{tabular}

${ }^{1}$ Total number of measures taken.

${ }^{2}$ Kappa value when the pair of observers took only 1 measure/farm.

${ }^{3}$ Median kappa value when the pair of observers took more than 1 measure/farm.

of the range. That is, if most producers scored close to $100 \%$, we probably missed problems. Alternatively, if most producers scored close to $0 \%$, then our targets were unrealistic.

Producers had median scores between 52 and $78 \%$ for all 9 critical areas (Table 7). Indeed, the $25 \%$ lowest scoring producers (25th percentile) scored up to $50 \%$ on 7 of the 9 critical areas and the maximum score of $100 \%$ was reached on 3 of the 9 areas. Most producers didn't reach targets (below 50\%) in some areas of calving management, care to newborn calves and painful procedures, colostrum management (Table 8), calf feeding (Table 9), and heifer housing (Table 10), and no producers (score 0\%) were able to reach 6 targets (out of a total of 39). Although we did not choose a representative sample of Quebec farms, the farms in our sample appeared to be typical of Quebec farms. We found the same management problems in our sample as we had seen in a previous epidemiological survey, which did involve a representative sample of Quebec dairy farms (Vasseur et al., 2010). The management practices that we identified included no use or inappropriate management of the calving pen; no systematic monitoring of the newborn; lack of pain control during painful procedures such as dehorning; no check of colostrum quality, intake, and passive transfer; no teat provided to satisfy the calf's motivation to suck; use of unpasteurized waste milk for unweaned calves; poor hygienic condition of heifer housing; and no pasture access. Therefore, we concluded that our tool would help producers or advisors identify practices that affect animal welfare and help the producers improve their management. Our targets were realistic so producers would not be discouraged from trying to improve their management.

\section{Encouraging the Involvement of Producers}

We evaluated the producers' perceptions of our tool because they are the end users of the tool and the best judges of the usefulness of an advisory tool. All producers $(100 \%)$ agreed that this tool was easily usable at the farm level and could help improve practices by giving new ideas and new material to reach targets of a good management. A majority $(68 \%)$ were in favor of using this tool for an animal welfare accreditation; the $43 \%$ against this idea mentioned that an accreditation involves too much record keeping and that they already have too much with the compulsory on-farm food safety program Canadian Quality Milk (Dairy Farmers of Canada, 2003).

Concerning the steps of the visit, $93 \%$ of producers agreed that the questionnaire on management took an acceptable amount of time and all producers (100\%)

Table 7. The minimum, 25th percentile (P25), median, 75th percentile (P75), and maximum score (\%) reached by producers for each critical area

\begin{tabular}{|c|c|c|c|c|c|c|}
\hline Critical area & No. of herds & Minimum & $\mathrm{P} 25$ & Median & P75 & Maximum \\
\hline Calving management & 28 & 22 & 35 & 52 & 73 & 100 \\
\hline Care to newborn calves and painful procedures & 28 & 6 & 36 & 56 & 64 & 86 \\
\hline Colostrum management & 28 & 31 & 53 & 58 & 65 & 85 \\
\hline Calf feeding & 28 & 30 & 50 & 59 & 74 & 94 \\
\hline Weaning & 28 & 46 & 63 & 68 & 72 & 100 \\
\hline Calf housing & 28 & 38 & 59 & 65 & 76 & 96 \\
\hline Heifer feeding & 28 & 40 & 66 & 78 & 83 & 94 \\
\hline Heifer housing & 28 & 44 & 58 & 73 & 77 & 83 \\
\hline General monitoring & 28 & 0 & 56 & 68 & 100 & 100 \\
\hline
\end{tabular}


agreed that the questionnaire was very important because it helped to evaluate routine management. All producers (100\%) agreed the evaluation of conditions in the barn took an acceptable amount of time (although the producers were not present for the data collection) and all of them (100\%) considered it very important to check environment-based data (e.g., size of calving pen). All producers $(100 \%)$ were very satisfied with the scoring; indeed, producers liked the approach by critical areas and targets and liked to have scores assigned. Finally, all producers $(100 \%)$ perceived the debriefing to be very satisfying and very important; indeed, producers liked this period of discussion where they received explanations of the scoring and recommendations.

Concerning the material provided (Figure 1), all producers $(100 \%)$ were in favor (easy to use, interest) of the calf passport and the colostrometer and thought of implementing them routinely. All producers (100\%) planned to implement routine supply of stocks of colostrum. Checking immunity transfer was not an easy task for approximately half of the producers (46\%) and the chief difficulty was in taking blood samples. However, only 6 producers (out of 28) asked for support and only 2 producers were still unable to take samples, even with help. This was probably the most difficult part of our tool because producers are not used to taking blood samples from newborn calves. In future uses of our tool, it might be advantageous to involve veterinarians in this step. However, the majority $(61 \%)$ of producers were convinced of the interest of checking immunity transfer. The concept of regularly checking Ig status, and the fact that commercial Ig kits are available, were new to the producers. Our goal in introducing these was to help producers to understand the direct effect of colostrum management on calf health and welfare and therefore the potential risks associated with poor management. For example, 3 producers experienced a negative test (i.e., failure of passive transfer); they explained that quality of colostrum was insufficient or that first colostrum feeding was delayed, and one producer used to routinely give only $0.5 \mathrm{~L}$ of colostrum. These 3 producers definitely understood the consequences of these actions when presented with data on the actual Ig status of their calves.

Even though the mortality and morbidity recording was considered as easy to do by all producers (100\%), not all of them $(77 \%)$ considered themselves assiduous enough to keep adequate records, but all of them $(100 \%)$ thought of implementing it routinely. Keeping records is something perceived as difficult for producers because it is often seen as an extra workload instead of a necessary part of calf rearing. Without good records of calf morbidity and mortality, it is difficult to judge the effectiveness of the producer's management on a

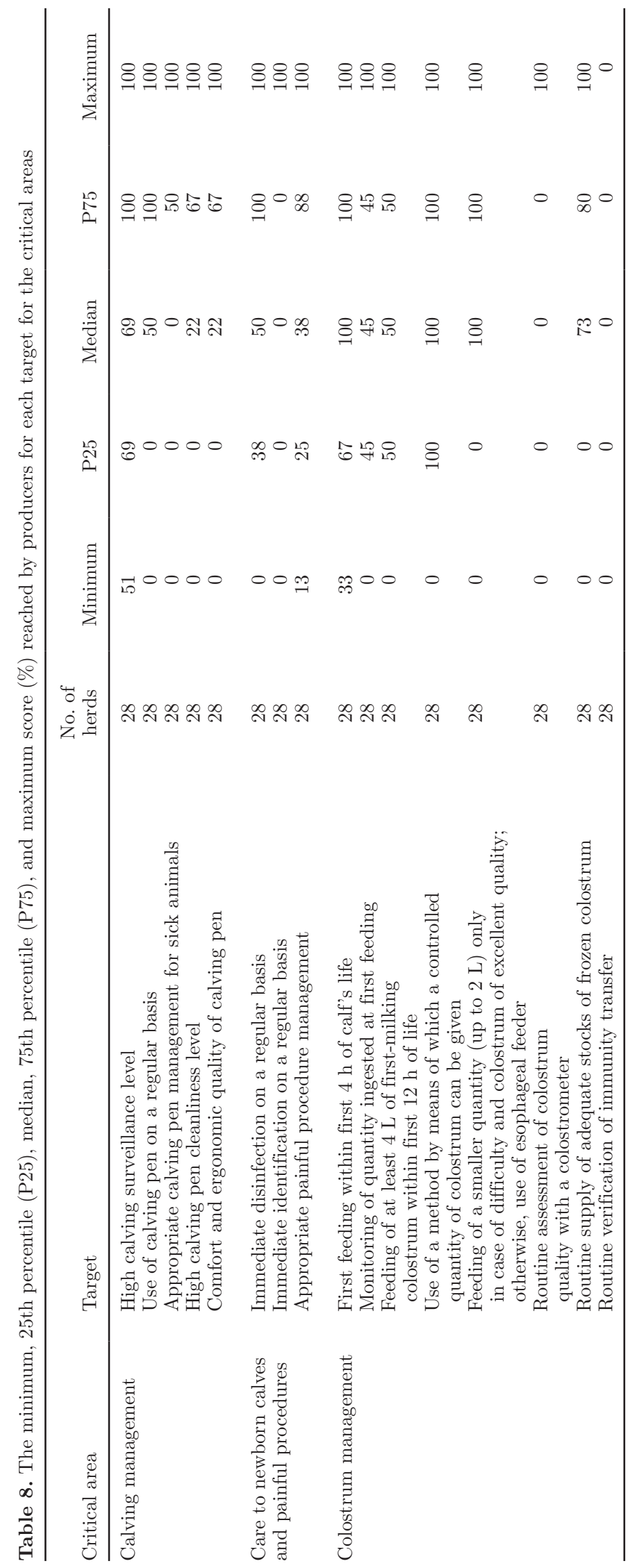


Table 9. The minimum, 25th percentile (P25), median, 75th percentile (P75), and maximum score (\%) reached by producers for each target for the critical areas

\begin{tabular}{|c|c|c|c|c|c|c|c|}
\hline Critical area & Target & $\begin{array}{l}\text { No. of } \\
\text { herds }\end{array}$ & Minimum & $\mathrm{P} 25$ & Median & P75 & Maximum \\
\hline \multirow[t]{5}{*}{ Calf feeding } & Milk feeding plan followed & 28 & 0 & 100 & 100 & 100 & 100 \\
\hline & Hospital milk not used & 28 & 0 & 0 & 0 & 100 & 100 \\
\hline & Access to water beginning on d 2 of life & 28 & 0 & 55 & 55 & 100 & 100 \\
\hline & Clean, functional waterers, unrestricted access & 28 & 0 & 30 & 55 & 80 & 100 \\
\hline & Clean, functional feeders, unrestricted access & 28 & 0 & 36 & 55 & 75 & 100 \\
\hline \multirow[t]{2}{*}{ Weaning } & $\begin{array}{l}\text { Age and concentrate consumption } \\
\text { adequate for weaning }\end{array}$ & 28 & 16 & 33 & 49 & 49 & 100 \\
\hline & Adoption of progressive weaning method & 28 & 0 & 100 & 100 & 100 & 100 \\
\hline Calf housing & Housing unit allows calf to be comfortable & 28 & 51 & 58 & 68 & 80 & 100 \\
\hline
\end{tabular}

long-term basis. Furthermore, the producers themselves do not know the results on their farm (e.g., we found that calf mortality was underestimated by $20-50 \%$, and $94 \%$ of producers perceived calf mortality as not being a problem; Vasseur et al., 2009b). This led us to provide materials to producers to help them develop the habit of keeping health records (goal 5).

\section{Effectiveness at Changing Management Practices}

The second way of judging the effectiveness of our tool (goal 3 for the first level) is through its long-term effect in changing management practices. Figure 2 shows the extent to which producers used various management practices before and 6 mo after the on-farm visit. These 15 practices were those that we were most interested in changing [i.e., these were the major risk factors detected in our risk factor assessment (Vasseur et al., 2010) and assessment by others (e.g., EFSA, 2006; NFACC, 2009)].

The importance of newborn calf monitoring seemed to be well understood by producers; many continued to use the calf passport to record newborn events, and 57 and $79 \%$ proceeded to practice immediate calf identification and navel disinfection, respectively. These were major improvements because before the on-farm visit, immediate calf identification and immediate navel disinfection were performed by only 14 and $43 \%$ of producers, respectively. The implementation of the calf passport was a surprise because producers generally considered record keeping to be an extra workload. Indeed, early monitoring is a recommended practice to

Table 10. The minimum, 25th percentile (P25), median, 75th percentile (P75), and maximum score (\%) reached by producers for each target for the critical areas

\begin{tabular}{|c|c|c|c|c|c|c|c|}
\hline Critical area & Target & $\begin{array}{l}\text { No. of } \\
\text { herds }\end{array}$ & Minimum & P25 & Median & P75 & Maximum \\
\hline \multirow[t]{3}{*}{ Heifer feeding } & $\begin{array}{l}\text { Clean, functional waterers, } \\
\text { unrestricted access }\end{array}$ & 28 & 25 & 75 & 75 & 75 & 100 \\
\hline & Access to forage feed at all times & 28 & 52 & 100 & 100 & 100 & 100 \\
\hline & Clean, functional feeders, unrestricted access & 28 & 33 & 56 & 67 & 67 & 67 \\
\hline Heifer housing & Access to pasture & 28 & 0 & 13 & 33 & 33 & 100 \\
\hline \multirow[t]{3}{*}{ General monitoring } & Mortality and morbidity record carefully kept & 28 & 0 & 75 & 100 & 100 & 100 \\
\hline & Monitoring of animals' growth & 28 & 0 & 0 & 100 & 100 & 100 \\
\hline & Hoof monitoring & 28 & 0 & 0 & 100 & 100 & 100 \\
\hline
\end{tabular}




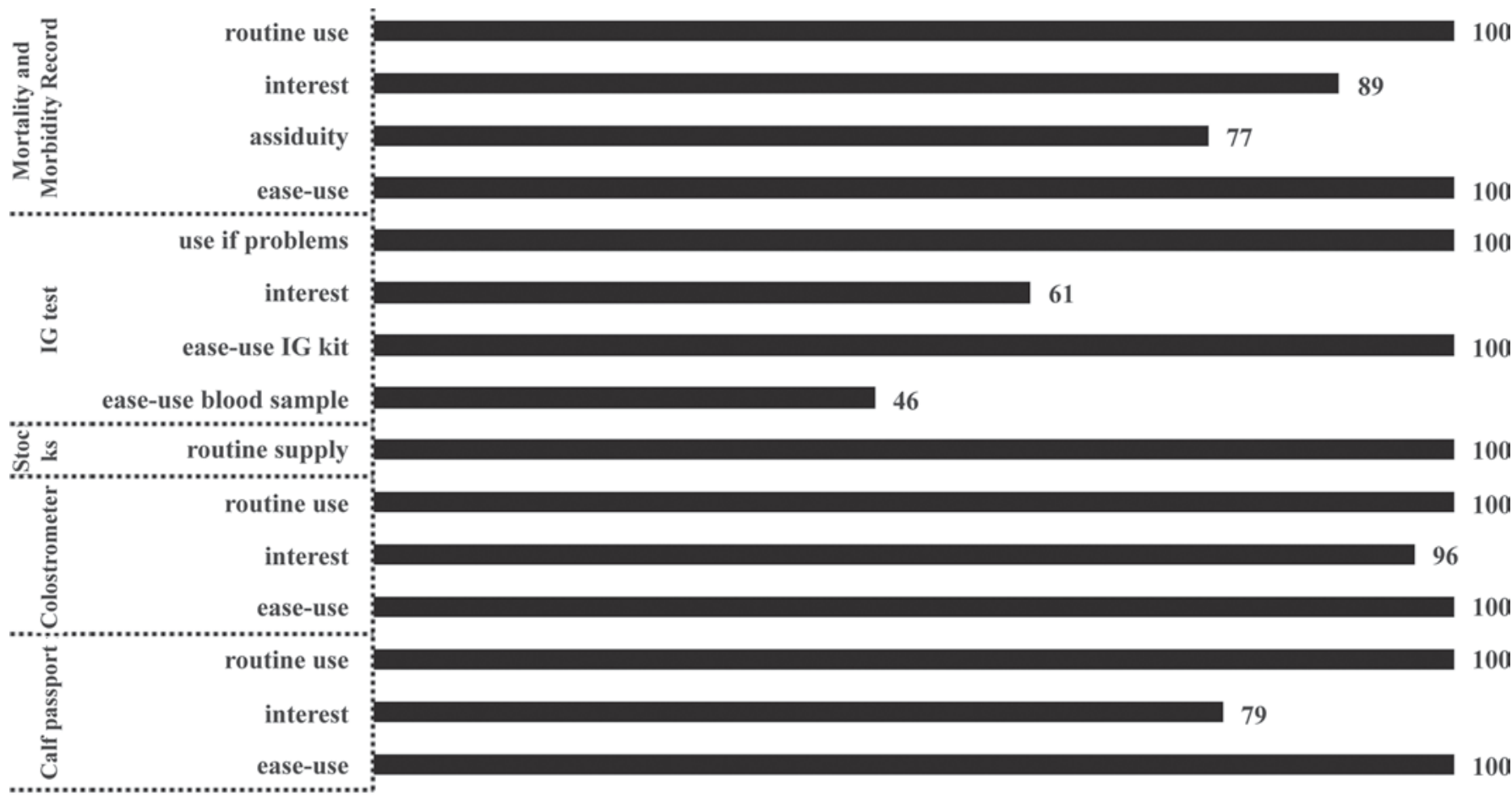

Percentage of PRO (\%)

Figure 1. Percentage of producers pro (in favor of) calf passport, colostrometer, stocks of colostrum, Ig test, and record of mortality and morbidity.

ensure individual follow-up and therefore an optimization of the newborn calf management (Quigley et al., 1996).

Major improvements were found for colostrum management. Six months after the on-farm visit, a first feeding of colostrum at $2 \mathrm{~h}$ after birth was done by $75 \%$ of producers (vs. only $39 \%$ before the visit), a first feeding of $4 \mathrm{~L}$ was done by $39 \%$ (vs. $4 \%$ before), a colostrometer was used by $29 \%$ (vs. $4 \%$ before), and stocks of colostrum were supplied by $64 \%$ (vs. $57 \%$ before); however, only $4 \%$ of producers continued to check immunity transfer on a routine basis. These increases showed the effectiveness of our advisory tool at improving most areas of colostrum management. Asking producers to take an active part in the project by training and learning new methods and by encouraging themselves to test that the information we provided was verifiable was a good way to change attitudes and to implement good practices to improve welfare.

We were interested in surveying the implementation of a feeding plan with a qualified advisor for calves because we found in our previous study (Vasseur et al., 2010) that most Quebec producers continued to apply traditional restrictive feeding (e.g., bucket-fed, low quantities of milk or replacer twice daily) despite the demonstrated advantages of feeding larger amounts of milk (Jasper and Weary, 2002; Khan et al., 2007). Six months after the on-farm visit, $81 \%$ implemented a feeding plan for unweaned calves (vs. $68 \%$ before) and $82 \%$ for weaned calves (vs. $79 \%$ before). However, despite increased risk for transmission of infectious pathogens to cattle and humans (Selim and Cullor, 1997), only $52 \%$ of producers did not use unpasteurized waste milk for calf feeding compared with $43 \%$ before the visit.

A standard operating procedure for dehorning was implemented by $57 \%$, whereas $50 \%$ implemented one before the visit. Hoof monitoring and growth evaluation were still high, with 82 and $86 \%$ of producers, respectively, performing them. Finally, $75 \%$ of producers implemented a record of mortality and morbidity, which is a welcome improvement. In our on-farm tool, we scored only for the good use of the record provided because only 10 producers kept a record for mortality and morbidity before the visit. Although producers generally found it time consuming to fill records, they finally adopted the practice.

\section{CONCLUSIONS}

We reached the main goals of a successful advisory tool of calf and heifer management to improve welfare on dairy farms. We respect the targeted 3 h-time limit. 
Record of mortality and morbidity events Hoof monitoring for heifer Growth evaluation SOP for dehorning

Feeding plan for weaned calf with advisor Feeding plan for non weaned calf with advisor No use of unpasteurized waste milk for calf feeding Verication of immunity transfer Supply of stocks of colostrum Use of colostrometer Feeding of $4 \mathrm{~L}$ of colostrum at first feeding Colostrum first feeding within calf's first $2 \mathrm{~h}$ Immediate calf identification Immediate navel desinfection Newborn calf's monitoring (Calf Passport)

\section{Do you use these Recommended Practices} routinely?

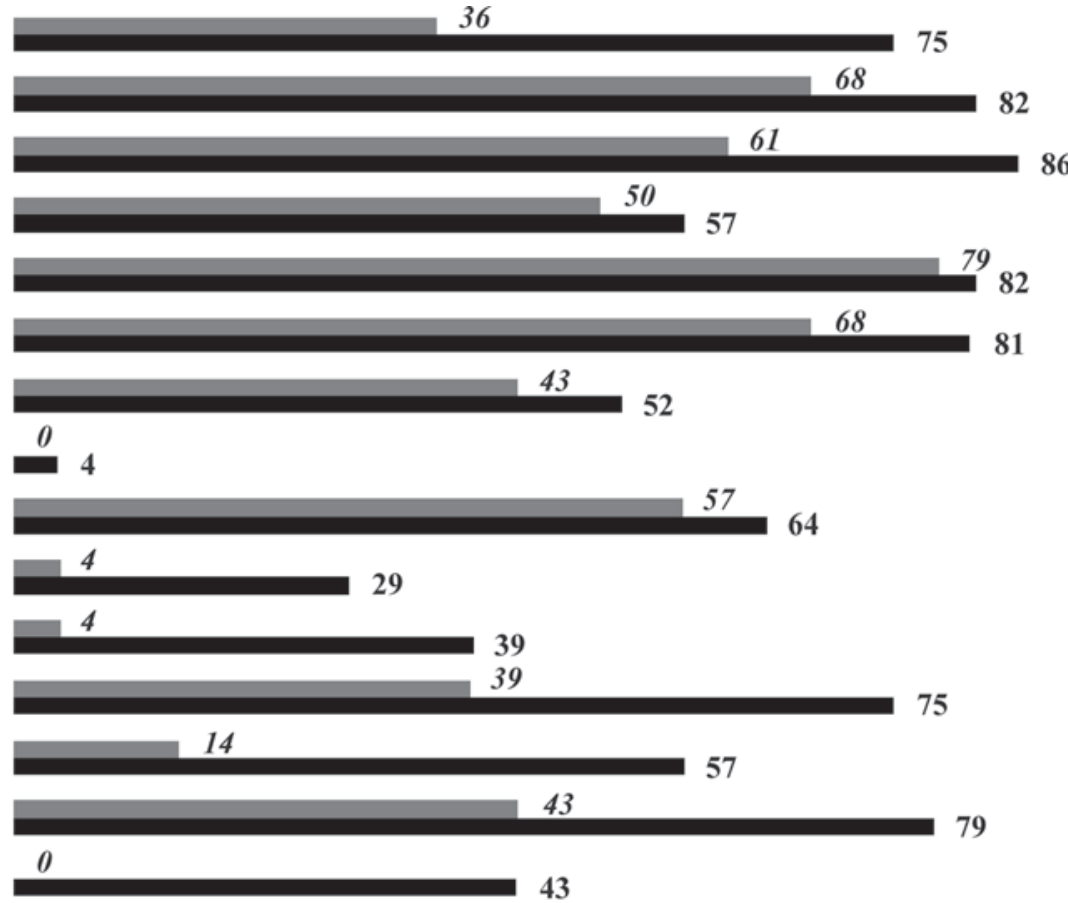

Percentage of utilization (\%) a Prior intervention $\quad 6$ mo After intervention

Figure 2. Percentage of producers that reported using in routine some recommended practices prior to and 6 mo after the on-farm intervention (no. of herds $=28$ ).

We had no problems collecting management- and environment-based data, and the repeatability of qualitative measures was usually good. Our tool was effective at identifying both good practices and problems, and our targets could realistically be reached by producers. The end users of our tool (i.e., producers) were convinced of the effectiveness of our tool as a diagnostic and aid decision tool. Our tool was effective at initiating changes in management practices.

An initial advisory approach for improving calf welfare is promising. Once necessary changes in management practices are voluntarily initiated as a result of producers changing their beliefs, attitudes, and behaviors (Dockès and Kling-Eveillard, 2006), the introduction of third-part audits (e.g., animal welfare accreditations by retailer) and legislation will have less of a negative effect on the dairy industry.

\section{ACKNOWLEDGMENTS}

We thank Novalait (Quebec City, Quebec, Canada) for its financial support, the experts committee for its helpful contribution, Elizabeth Carbonneau and Véronique Bouffard (both of Laval University, Quebec City, Quebec, Canada) for their excellent work in de- veloping the tool and collecting data, the producers for their active participation, and Valacta (Sainte-Annede-Bellevue, Quebec, Canada) technical advisors and veterinarians.

\section{REFERENCES}

Bockstaller, C., and P. Girardin. 2003. How to validate environmental indicators. Agric. Syst. 76:639-653.

Dairy Farmers of Canada. 2003. Canadian Quality Milk on-farm food safety program. Reference manual. Agriculture and Agric-Food Canada, Ottawa, Ontario, Canada.

De Rosa, G., C. Tripaldi, F. Napolitano, F. Saltalamacchia, F. Grasso, V. Bisegna, and A. Bordi. 2003. Repeatability of some animalrelated variables in dairy cows and buffaloes. Anim. Welf. 12:625629 .

Dockès, A. C., and F. Kling-Eveillard. 2006. Farmers' and adviser' representation of animals and animal welfare. Livest. Sci. 103:243-249.

EFSA. 2006. The risks of poor welfare in intensive calf farming systems. An update of the Scientific Veterinary Committee Report on the Welfare of Calves. EFSA-Q-2005-014. European Food Safety Authority, Parma, Italy.

Harbison, J. L., M. R. Slater, and L. M. Howe. 2002. Repeatability and prediction from a telephone questionnaire measuring diet and activity level in cats. Prev. Vet. Med. 55:79-94.

Jasper, J., and D. M. Weary. 2002. Effects of ad libitum milk intake on dairy calves. J. Dairy Sci. 85:3054-3058.

Khan, M. A., H. J. Lee, W. S. Lee, H. S. Kim, K. S. Ki, T. Y. Hur, G. H. Suh, S. J. Kang, and Y. J. Choi. 2007. Structural growth, rumen development, and metabolic and immune responses of 
Holstein male calves fed milk through step-down and conventional methods. J. Dairy Sci. 90:3376-3387.

Lensink, B. J., C. G. van Reenen, B. Engel, T. B. Rodenburg, and I. Veissier. 2003. Repeatability and reliability of an approach test to determine calves' responsiveness to humans: A brief report. Appl. Anim. Behav. Sci. 83:325-330.

March, S., J. Brinkmann, and C. Winkler. 2007. Effect of training on the inter-observer reliability of lameness scoring in dairy cattle. Anim. Welf. 16:131-133.

Mitchell, G., A. May, and A. McDonald. 1995. PICABUE: A methodological framework for the development of indicators of sustainable development. Int. J. Sustain. Dev. World Ecol. 2:104123.

NFACC. 2009. Code of practice for the care and handling of dairy cattle. National Farm Animal Care Council, Lacombe, Alberta, Canada.

Quigley, J. D., III, C. S. T. Nyabadza, G. Benedictus, and A. Brand. 1996. Monitoring replacement rearing: Objectives and materials and methods. Herd health and production management. Pages 75-102 in Herd Health and Production Management in Dairy Practice. A. Brand, J. P. T. M. Noordhuizen, and Y. H. Schukken, ed. Wageningen Press, Wageningen, the Netherlands.

Rousing, T., and S. Waiblinger. 2004. Evaluation of on-farm methods for testing the human-animal relationship in dairy herds with cubicle loose housing systems-Test-retest and inter-observer reliability and consistency to familiarity of test person. Appl. Anim. Behav. Sci. 85:215-231.

Rushen, J., A. M. de Passillé, M. A. G. von Keyserlingk, and D. M. Weary. 2008. The Welfare of Cattle. Springer, Dordrecht, the Netherlands.

Selim, S. A., and J. S. Cullor. 1997. Number of viable bacteria and presumptive antibiotic residues in milk fed to calves on commercial dairies. J. Am. Vet. Med. Assoc. 211:1029-1035.

Stull, C. L., B. A. Reed, and S. C. Berry. 2005. A comparison of three animal welfare assessment programs on California dairies. J. Dairy Sci. 88:1595-1600.

Tozer, P. R., and A. J. Heinrichs. 2001. What affects the costs of raising replacement dairy heifers: A multiple-component analysis. J. Dairy Sci. 84:1836-1844.
USDA. 2008. Dairy 2007, part III: Reference of dairy cattle health and management practices in the United States, 2007. No. N482.0908. Centers for Epidemiology and Animal Health, USDA-APHIS-VS, Fort Collins, CO.

Vasseur, E., F. Borderas, R. I. Cue, D. Lefebvre, D. Pellerin, J. Rushen, K. M. Wade, and A. M. de Passillé. 2010. A survey of dairy calf management practices in Canada that affect animal welfare. J. Dairy Sci. 93:1307-1315.

Vasseur, E., J. Rushen, and A. M. de Passillé. 2009a. Does a calf's motivation to ingest colostrum depend on time since birth, calf vigor, or provision of heat? J. Dairy Sci. 92:3915-3921.

Vasseur, E., J. Rushen, A. M. de Passillé, D. Lefebvre, G. Fecteau, and D. Pellerin. 2009b. A diagnostic tool to assess calf welfare and management on-farm. J. Dairy Sci. 92(E-Suppl. 1):501-502.

Veissier, I., A. Butterworth, B. Bock, and E. Roe. 2008. European approaches to ensure good animal welfare. Appl. Anim. Behav. Sci. 113:279-297.

von Borell, E., F. J. Bockisch, W. Büscher, S. Hoy, J. Krieter, C. Müller, N. Parvizi, T. Richter, A. Rudovsky, A. Sundrum, and H. Van den Weghe. 2001. Critical control points for on-farm assessment of pig housing. Livest. Prod. Sci. 72:177-184.

Weaver, D. M., J. W. Tyler, D. C. VanMetre, D. E. Hostetler, and G. M. Barrington. 2000. Passive transfer of colostral immunoglobulins in calves. J. Vet. Intern. Med. 14:569-577.

Whay, H. R. 2007. The journey to animal welfare improvement. Anim. Welf. 16:117-122.

Whay, H. R., D. C. J. Main, L. E. Green, and A. J. F. Webster. 2003. Assessment of the welfare of dairy cattle using animal-based measurements: Direct observations and investigation of farm record. Vet. Rec. 153:197-202.

Winckler, C., Knierim, U., Lensink, J., Vasseur, E., Pellerin, D., Rushen, J. and A. M. de Passillé. 2006. Development of a monitoring system for dairy calves and rearing heifers. Full proposal, Welfare Quality project. Welfare Quality ${ }^{\circledR}$ Consortium, Lelystad, the Netherlands. 